Pre-print Communications in Communication and Information Science 2014

\title{
MOOCs: What Motivates the Producers and Participants?
}

\author{
Su White ${ }^{1}$ Hugh Davis ${ }^{1}$, Kate Dickens ${ }^{1}$, Manuel León ${ }^{1}$ and $\mathrm{M}^{\mathrm{a}}$ Mar Sánchez-Vera ${ }^{2}$ \\ ${ }^{1}$ Centre for Innovation in Technologies and Education, University of Southampton, Highfield, \\ Southampton, UK \\ ${ }^{2}$ Department of Didactics and School Organisation, University of Murcia, Murcia, Spain \\ $\{\mathrm{su}, \mathrm{hcd}, \mathrm{kate}$. dickens, ml4c08\} soton. ac.uk mmarsanchez@um.es
}

\begin{abstract}
Within the current educational landscape, Massively Open Online Courses (MOOCs) have stimulated extensive interest and hype in a short time. It has been asserted that these open courses are no more than a prelude to the disruption that traditional Higher Education Institutions will experience from the growth of on-line education. Meanwhile, institutions are making increasingly significant investments to produce MOOCs, and learners are enthusiastically enrolling in large numbers, often in tens of thousands. The analysis presented identifies a spectrum of motivating factors for universities, and suggests likely areas for future attention and developments. It further identifies a range of motivations for learner participation, which may not be identical across cultures and which MOOC providers might wish to take into account.
\end{abstract}

\section{$1 \quad$ Introduction}

In September 2013 the first UK based MOOC platform, FutureLearn, announced twenty new MOOCs. Running in the final quarter of 2013 they included the University of Southampton's first MOOC "Web Science: how the web is changing the world". This paper presents part of our attempt to answer the questions "why are we doing this?" and "why would the learners want to study MOOCs?"

These questions are worthy of discussion at a time when the landscape for higher education is widely predicted to change mainly because of the way the web is changing the world. Some claim that business models for higher education are about to collapse in much the same way that the music industry's business model collapsed in the 2000's; and possibly MOOCs are the Napster in this scenario [1]. One apparent response to these predictions is real financial investment: text book publishers are rapidly re-inventing themselves as purveyors of on-line education, and lobbying government for a level playing field with universities; and venture capitalists are lining up at universities' doors trying to buy into a share of their more popular courses. Venture capitalists expect quick profits, so they are presumably anticipating rapid disruption.

In 2013, universities have invested greater sums of money in developing single MOOCs than they have been accustomed to investing in the development of yearlong courses. If MOOCs are at the frontier of disruption, then what is the motivation for 
universities to embrace them rather than resist them? Our research on motivations for universities was carried out as a meta-review of the literature. 2012 was the year in which many MOOCs became available, mostly through Coursera, edX and Udacity in the USA. These MOOCs have now been evaluated and we are beginning to see papers published, but at the time we began this research there were few academic articles and to track the emerging phenomena of MOOCs it was necessary to also observe the web-based grey literature of journalistic articles, blogs and social media.

Learners are registering for MOOCs in an enormously wide range of subjects in their tens of thousands. Apparently they are not motivated by grades since in most MOOCs there are no grades. So it is valid to ask why these students are so interested in studying MOOCs.

\section{$2 \quad$ Methodology}

Two research perspectives have been adopted.

1) Investigating the motivations of Higher Education Institutions (HEIs) to engage with MOOCs. A qualitative approach using content-analysis was conducted across a set of around considering whether or not HEIs should foster MOOCs.

2) Learners' motivations for participation. An online survey was conducted to gather information from MOOC participants. It looked in depth into the reasons why learners decided to register and elicited some reflections on their beliefs, attitudes and behaviours when participating in a MOOC. The questionnaire was analysed primarily by using a quantitative method of frequencies of responses. In carrying out our research on student motivation we wished to get beyond the survey of the set of students that completed a particular MOOC and to investigate some of the cultural differences in motivations, so our results are based on a survey circulated by social media within the UK, Spain and Syria.

\subsection{Methodology: HEIs' motivations}

\section{Identification and selection of sources.}

Selected contributions, published in three different domains, were used: namely education technology journals; HE magazines; and blog posts. The sources were identified by using different search strategies depending on the domain where the literature was published. For the peer-reviewed academic literature in journals, the method used was inspired by the identification of sources in the systematic literature review [2] carried out in 2013. The journalistic and blog (grey literature) sources were drawn from the curated collections of four educational technologists via the Scoop.it social media site over the four months prior to August 2013. These MOOC-focused curations drew on a wide range of sources of which a more reduced number were in turn chosen for this project, seeding by provenance and perceived authority and encompassing views which were either for or against the adoption of MOOCs in HEIs. Sources were primarily selected according to their relevance to the topic of MOOCs in HEIs. 
1) Academic literature - to identify the drivers of the emergence of MOOCs.

2) Grey literature - for identifying current debates.

More rigour was credited to peer-reviewed journal articles, than to journalistic pieces and blog posts. Therefore, the selection of the papers was focused on its content and relevance. The selection of grey literature placed greater emphasis on authorship and provenance because, as noted by Daniel [3], the media contain abundant literature in which the intention of promoting MOOCs as products for profit seeking undermines the objectiveness of the judgements towards their potential to improve the education delivery.

\section{Analysis of sources.}

Herring's [4] adaption of Krippendorf's [5] Content Analysis (CA) method for online context was used with the academic and journalistic corpora of MOOC related sources. Apart from identification and selection of sources explained above, CA involves establishing categories into which the arguments in the sources are to be distributed into three contexts. These contexts were a) open education movements; b) the evolution of technology in distance education; c) disruptive innovations in education. Because they were more opinion loaded, non-academic sources were classified into debates of sustainability, quality, and impact of MOOCs from an institutional perspective [6].

\subsection{Methodology: learners' motivation}

Analysing the intrinsic and extrinsic motivation that leads a learner to take the decision to register in a MOOC is not easy because there are many cognitive and affective components involved. A MOOC heavily relies on the autonomy of the student to control their learning process. Termed "Self-regulated learning" (SRL), this concept which emerged in the " $80 \mathrm{~s}$, addresses the question of how students manage learning process, and includes cognitive strategies, metacognition and motivation [7]. Motivation is an important part of the SRL. Specifically, intrinsic motivation is needed to perform learning tasks as part of the forethought, the strategic process that precedes performance in learning [8]. However, it is more feasible to understand the reasons that may lead a person to consider undertaking a MOOC. The data was gathered through a questionnaire, from an empirical analytical perspective. The questionnaire contains 24 questions, grouped by the following themes:

- About you. This section's goal was to obtain basic information about the participants: residence, age, gender, occupation and kind of learner.

- Education. Focused on level of education and whether parents attended university.

- MOOC providers. To know if people had participated in any MOOC before, when it was, when and where they accessed to materials and what device they used.

- Motivation. Designed to identify which MOOC platform was used, how many MOOCs studied, if they interacted with others, tools used in the MOOC experience, activities developed, and finally, questions relating to reasons for starting a MOOC, and for completion. 
The survey was designed and piloted. It was also translated into Arabic and Spanish, to obtain data from those language environments. The questionnaire was published using the University of Southampton web based survey tool iSurvey. The participants were recruited through Facebook, Twitter and email. Once the data was collected, it was analysed through SPSS software. The categorising and coding process of the variables for the questionnaire was related to the type of question (mainly nominal) and a direct reading of the data was made by frequency calculation.

\section{Findings: Motivations for Higher Education Institutions}

\subsection{MOOCs in context.}

The analysis of the two sets of sources generated a number of observations on the institutional motivations and reactions to MOOCs. The main observations in terms of the established contexts of the emergence of MOOCs determined by the analysis of academic sources, were as follow:

- Strategic Growth: Marshall [9] argues that developing MOOCs is part of HEI strategic plans to remain competitive in the market for learners seeking an affordable education balancing the 'bargaining power of buyers' and the 'bargaining power of [competitor HEI] suppliers'.

- Marketing: Delarocas \& Alstyne [10] observe that MOOCs are often introductory courses that contribute to a marketing recruitment strategy targeting large numbers of potential fee paying students.

- Strategic Collaboration: Universities are gathering in consortia around emerging MOOC platforms, such as Coursera, FutureLearn and EdX. The University of Edinburgh's report [11] identified belonging to peer communities as a way to explore new educational methods, and secure greater reach and more presence for courses.

- Organic Growth/Evolution: Yuan \& Powell, [12] argue that MOOCs emerge as a natural evolution of Open Educational Resources (OERs). HEIs, especially those already championing OERs, such as Harvard and MIT are compelled to sustain Open Education within this new format.

- Response to Learners: Castells' influential analyses of contemporary societies [13] emphasises use of available technologies to engage in networked interactions, in the 'networked society'. Williams et. al., [14] observe that learners are not only ready to learn collaboratively through social media but also demand it. This trend has permeated the education domain, and leading HEIs must develop pedagogical approaches that fulfil these demands if they want to maintain their top positions in the rankings.

- Learner Analytics: MOOCs produce large quantities of learner data. This is valuable data that can inform the design of enhanced, customised and effective instructional methods, which may in turn raise the perceived quality of tuition in universities, and hence improve competitiveness. Analysing these datasets can shed light on collective and individual learning processes [15]; learners' engagement levels in different course stages [16]; or their potential for success or failure [17]. 
- Educational Enhancement: Taken collectively the observations above also suggest that educational enhancement is either a sub-objective or a fortunate consequence of MOOC participation.

\subsection{Main debates on MOOCs.}

An extensive survey on the contemporary grey literature identified three areas in which the debates were more frequent and intense. Within sustainability two main themes occupied most of the debates, 1) analogies with other business initiatives; 2) learners' sustained participation.

The business analogy of sustainability, championed by Marginson [18], Young [19] and the Economist [20] draws parallels between MOOCs and successful business models of Silicon Valley initiatives such as Google and eBay, who made early investments, provided free services, and now make substantial profit. Weston, [21] presents another side of the debate citing the experience of companies who suffered the dotcom bubble; Ptascynsky [22] suggests that universities will realise that they do not external platforms to run MOOCs, since universities can provide fairly feasible technological solutions without the need for third parties.

The sustainability of learners' participation, debate has optimist commentators such as Lawton \& Katsomitros [23] arguing that high numbers of enrolling students provide an opportunity for novel sustainable business models whereby some costs are met by institutions, governments and future employers while students pay for assessment and certification.

However, the interpretation of the high drop-out rates is contentious and relate to the quality of provision as well as sustainability. Sceptics like Tauber, [24] see them as a serious issue rooted in poor conceptualisation and design. Kollowitch [25,26] illustrates the failure of MOOC models with concrete examples, such as the bad experiences with MOOCs of Colorado State University and San Jose State University. However Catropa, [27] suggests this sceptical view is mistaken underestimating the high number of students who actually complete a MOOC despite the high drop-out rates while Parr, [28] claims it ignores the fact that many learners who do not complete a MOOC still benefit.

There were frequent debates in the media regarding the quality of MOOCs. Sceptics see them as not being able to reproduce the discussions that takes place in small face-to-face group settings, which are deemed as the only way meaningful learning can take place [29]. A frequent counterargument is that seminar discussions can and have been reproduced successfully in web-based environments [30]. Also, many recognise that MOOC tuition quality might be lower due to the ratio of students to teacher, but it is still reasonable for those who will otherwise not access HE [31].

A further motivational factor to HEI involvement in MOOCs is their impact and spread. Lewin, [32] compares it with a tsunami; the more universities join the movement, the more universities will be urged to join it. This tsunami will fuel a revolution in HE. However, sceptical views, such as that of Drezzner [33], situate the current enthusiasm in the beginning of a hype cycle that will soon deflate. 


\section{MOOCs as Distance Education.}

The literature identifies six distinct generations of distance education associated with the role of technology in each step: $[34,35,36,37,38]$ MOOCs can be considered alongside this timeline.

- First generation: a "correspondence model", studying via mail.

- Second generation: incorporated technologies such as video.

- Third generation: combining tools and telecommunications [34], also referred to as "telelearning", e.g. incorporating the use of videoconferencing. It is also the moment when educational concepts as "open education" and "flexible learning" emerge.

- Fourth generation: "the flexible learning model" Taylor [35] emphasises the use of technology and the Internet in the '90s producing the first eLearning experiences.

- Fifth generation: adds the emergence of Virtual Learning Environments (VLE), the use of Virtual Campus and resources processes characterised by automation systems Taylor [36].

- Sixth generation: based on Web 2.0, like a model of progress of interactive environments technology has changed [38], an increase in social software tools. Blogs, wikis and social networks have changed the way people use the Internet, and represent new opportunities to learn.

Perhaps MOOCs will become the seventh generation in distance education. Clearly they enact a model of distance education. The current "boom" in the university narrative created by MOOCs suggest some turning point in distance education. Although perhaps in terms of a formalized educational understanding of MOOCs it is rather early to make that claim.

\section{MOOCs Structure and Assessment.}

Two distinct kinds of MOOC are widely recognised: xMOOCs and cMOOCs. The xMOOCs focus on courses content and are typically located on a single web platform. Course development is usually centred on that platform, which provides access to the contents. cMOOCs are related to connectivistm incorporating the design and realisation of networked learning and based on the ideas of Siemens [39,40] They start from the idea that we learn when we connect with other people, accordingly cMOOCs manifest in a more open format working with social and collaborative tools.

In early MOOCs, the opportunity provided by participating in a MOOC was not to primarily obtain a certificate, but to learn. This aspect of cMOOCs is highlighted because "participation in a MOOC is emergent, fragmented, diffuse, and diverse. There is no credit or certificate offered for completion" [41].

More recently, many MOOCs, particularly, xMOOCs, offer certification (free or charged), providing participants the chance to formally record their learning and thereby to improve their CV. O'Toole [42], in a discussion paper looking at peer assessment, asserts that "whereas in the cMOOC participants are primarily interested in building the collective capabilities of the whole network, and hence are more likely to use feedback and ratings systems honestly, in xMOOCs participants are aiming to get 
a good personal grade". A demand for validated certification exists and some companies are beginning to sign agreements with institutions to provide MOOC participants with such services e.g. the agreement between Udacity and Pearson to create a network of assessment centres, and a similar agreement between Miriadax, the Spanish MOOC platform and Telefonica.

\section{Motivations: Learners}

\subsection{Findings}

A total of 258 questionnaires were completed: 52 English, 193 Arabic, 40 Spanish. The majority of respondents were in the 18-24 age range with variations depending on the language identified in the survey. Majority are male respondents $(72.5 \%)$ :

\begin{tabular}{|l|l|}
\hline English & $67.3 \%$ male \\
\hline Arabic & $77.2 \%$ male \\
\hline Spanish & $48.7 \%$ male \\
\hline
\end{tabular}

Table 1. The majority of respondents were male.

A large volume of interesting data have been obtained from this questionnaire, however, the remainder of this paper will focus on motivation related data, concentrating on reasons that led respondents to participate in a MOOC. In this section, respondents could choose from a number of options and could check more than one. Carefully analysing these data, a number of reasons normally found in the web and scientific discussions, appear to be confirmed. Figure 1 shows all options:

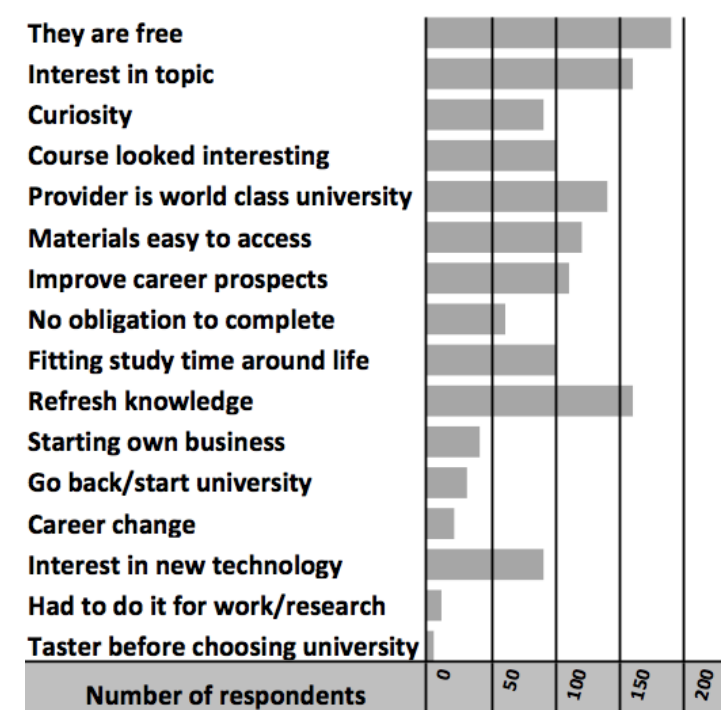

Fig. 1. Distribution of responses identifying motivation. 
The analysis below explores the findings, indicating whether or not they underpin the widely perceived motivations of learners in MOOCs.

\section{MOOCs are free and open.}

Free availability is the important factor according to the survey selected by $67 \%$ a particularly high number of respondents from the Spanish questionnaire selected this option (72.5\%). Providing educational resources for free is not new and open licensing for software, resources and learning objects is well established. MIT launched the Open Course Ware project (OCW), in 2001 to share web-based teaching materials under Creative Commons licenses. The main difference between MOOCs and OCW is that while initiatives like OCW focus on sharing teaching materials, Universities are using MOOCs to realise a complete learning process. Learners are not only able to access the material, but they can also follow lessons, develop activities, talk with online-classmates, and even be evaluated. Cost free and usually open.

If free is a fundamental aspect that motivates students to follow a MOOC, and it would be interesting to know which aspect of this liberation is most relevant to them.

\section{MOOCs are convenient: fitting around life.}

There are clear differences in motivation related to fitting study time around life, in general, this selection is not chosen by a lot of people (36\%), but it is of interest. The Arabic responses show $27.5 \%$ interested in this aspect, the Spanish represents $65 \%$. The majority of Spanish participants are in full time employment which may be the reason that they rate this aspect as relevant.

\section{MOOCs for CV and knowledge update.}

There were two possible responses related to professional expertise 1) A MOOC helps to improve my CV 2) A MOOC helps to update knowledge. Both these perspectives may relate to professional expertise.

The question 'A MOOC helps to improve my CV' appears more related to the need for certification to be shown in a CV. In the survey, improving $\mathrm{CV}$ is selected by $54.4 \%$ of all participants as one reason to use a MOOC, but the percentage rises to $61.7 \%$ of Arabic participants, probably because the majority are students. This is consistent with other studies, for example findings at Duke University [43] highlights it as the main reason students participated. A MOOC helps to update knowledge. $59.1 \%$ of Arabic and $70 \%$ of Spanish participants said that one main reason to do a MOOC is to refresh knowledge.

\section{The Social community of MOOCs.}

MOOCs may have social components that motivate learners to register to participate. Respondents affirm (55.8\%) they were the first among acquaintances, family, colleagues and friends participating in a MOOC. However 124 respondents from 285 found out about MOOCs via social media and then decided to participate. MOOCs can represent an opportunity for socialisation. 


\section{MOOCs satisfying interest and usefulness.}

In a market with a lot of options, MOOCs can represent a new way to learn and access digital content. Interest in the topic is one important reason for participating in a MOOC, specifically $56.8 \%$ overall, $80 \%$ of respondents in the English language selected this aspect. Usefulness also features; $60.6 \%$ of participants overall declare they will use the knowledge gained during the MOOC in a personal project, and $63.2 \%$ in personal development These data follow the same line as other research, such as Duke University, where the topic was identified by $87 \%$ of the students as a motivational aspect [43]. Many students indicated that they thought the course would be fun and enjoyable. This aspect of 'edutainment' where usefulness and fun intersect may be of real importance.

\section{MOOCs enable learning with the best.}

The origin of MOOCs in prestigious universities, or by the effort of high profile or world leading academics may explain their apparent popularity and rapid growth and their power to attract the attention to many different learners. Although not quite the majority, about half the respondents, $48.1 \%$, identified 'provider was a word class university' as a reason for participation. There is some difference by origin of respondents. English language respondents show the least interest at 38.5\%; Spanish 43\%; Arabic 51.8\%.

\section{MOOCs professional development and lifelong learning.}

The University of Edinburgh report summarising of the experience of their six Coursera MOOCs in May, 2013 [11] observed "In general, we attracted adults with high educational attainments". That is reflected in the survey, 208 of the 282 have a degree (mainly undergraduate 133 of 285 . There are more post-doctorate learners in English and Spanish language respondent than in Arabic.

The largest represented age range (50,5\%), is between 18 and 24 but there are a lot of differences depending on the scope: Most Arabic language respondents are in the range of 18-24 years old, this percentage decreases in English and even more so in the Spanish language results, in where the largest represented age range is the 25-34 years old.

Motivations for 18 to 34 years may be closely related to the opportunity to improve their career, moreover, enhance their professional network. Half the respondents indicated that participating in a MOOC enabled them to enhance their professional development and improve their knowledge in the workplace. Among Spanish speaking the percentage identifying this as an important factor rises to $77.5 \%$.

The survey asked how respondents would use the knowledge gained in the MOOC. The most widely identified factors were personal development and projects. In a world increasingly multidimensional and diverse, MOOCs can work in universities as a piece of the system providing open learning opportunities, forming part of the learners' personal learning network. Professional and personal development needs are increasing alongside rapid business change. Therefore, MOOCs can offer a learning opportunity for people to develop lifelong learning. 


\section{$5 \quad$ Issues}

\subsection{Pedagogic possibilities or illusion?}

The UK Department for Business, Innovation and Skills extensively reviewed the MOOCs literature in 2013 [44]. They identify two trends in educational press, blogs and general media. One enthusiastically promoting MOOCs, reporting positively on learning experience and innovative forms of pedagogy, focusing on concepts like collaboration and community. But the sceptical view sees two major flaws: the supposed benefits of MOOCs are the victory of content packaging; and the MOOC format itself is exclusive and does not have enough quality to develop skills in learners.

Educational technologists have long argued that learning online is not only about content. Bates [45] suggests that open and flexible education should consist of the provision of flexible learning, built around geographical, social, and time constraints of each student, instead of being built around educational institutions' needs. How can a MOOC, developed for hundreds or thousands of students, meet these aspirations? Educationally, MOOCs are only a small part of the multiplicity of wider international university systems. They cannot be assumed to be the panacea that will solve all educational problems.

Moreover, the very high drop-out rate behind MOOCs is widely recognised. Clow et al. [46] categorise that phenomena as "the funnel of participation". The funnel consists of four stages of participation: awareness; registration; activity and progress. What is not known is the extent of the participants' satisfaction with their (perhaps very limited) participation. However, "bad experiences" with MOOCs have been reported. In July 2013 "Inside Higher Ed" [47] reported that, after six months of highprofile experimentation, San Jose State University plans to "pause" its work with Udacity, because "preliminary findings from the spring semester suggest students [in online joint Udacity/San Jose courses] do not fare as well as students who attended normal classes".

\subsection{Assuring assessment for learning}

The volume of learners in MOOCs perhaps inevitably makes feedback and the assessment two highly debated aspects of MOOCs. MOOCs are demonstrations of assessment online and at scale. Since technologies allow focus upon and tracking of the student learning process, e-assessment need not be an action that occurs only at the end of the course. However, taking into consideration skills and other aspects of the learning process, there is a lack of systems that facilitate a complete assessment, (Strither; Driscoll; Radenkovic et all) [48, 49, 50].

Additionally, the "massive" (independent and remote) nature inherent to MOOCs, makes it more difficult to develop high quality assessment. Although some MOOCs incorporate "peer assessment", O'Toole [42] notes that, rather than peer assessment, it should be called "peer-grading", since it cannot be assumed that an equal or adequate level of understanding about assessment is possessed by all MOOC learners. 
Another desirable and thus important aspect of the learning process is feedback, assessment for learning. Feedback on assessment online is not always integrated in the mechanisms that assess students. It is challenging in a MOOC environment to develop effective assessments where, feedback reinforces learning and identifies inconsistencies in the learner process.

\subsection{Costs - benefit or risk?}

MOOCs are in principle free for students, although some platforms now incorporate a fee for a certificate of participation. MOOCs are not free for institutions. Universities have to invest time and money designing and uploading materials, managing the course, providing feedback. It is not clear if this model is sustainable over the time. Luján [51] discusses an interesting perspective that the most important American universities may be using MOOCs to protect themselves against a possible outbreak of "the bubble of Universities". This stresses the hypothesis that a MOOC can work for universities as an initiative to contain costs and enrol more students, thus obtaining more revenue and helping to resolve the crisis in the sector. Yuan and Powell [12] suggest that companies may want to invest in MOOCs in order to enhance the company brand or create a new income stream from Higher Education business. Such motives may lie behind companies signing agreements with institutions to provide services for MOOCs, such as the contract between Pearson and Udacity to create a network of evaluation centres.

\subsection{Widening inequalities.}

MOOCs can create inequalities at different levels: among students, across educators, between institutions, and even at a global level. Regarding students, Cookson [52] points out that job seekers with MOOC certificates will pose weak competition to those with traditional degrees. Carlson \& Blumerstyk [53] note that the skills needed in a tertiary sector driven economy such as talking in public or business etiquette can only be acquired through face-to-face tuition. Those who most need these skills are the most disadvantaged, mainly due to their social backgrounds, and MOOCs may not be able to empower them.

Educators may also face inequalities following a massive adoption of MOOCs. While scalability allows elite 'superstar' professors to reach massive audiences, it may leave the rest of educators in precarious conditions [54]. At institutional level, universities that can afford the costs of engaging in MOOCs may leave competitor institutions with little market share, as massive uptake could lead to centralisation. Although widely contested, Thrun's prediction that only a few universities would be needed in the world [55] may have validity.

Finally, at a global level, Sloep [56] explains that, far from promoting inclusion, MOOCs promote cultural imperialism, because "developing countries lack the financial and human resources to develop an educational system of high quality, so when they are confronted with MOOCs they cannot afford the luxury of refusing them". 


\subsection{Learners' digital competencies.}

MOOCs require, and develop a range of specific skills. Early reports on MOOCs identify a clear profile of prior-experienced participants who are post-graduates and/or professionals $[11,57]$. Brown [58] suggests undergraduate students are less likely to possess the skills needed by an autonomous learner in a MOOC. However, a cross-section of people who are less likely to have these skills can and do enrol. It would be interesting to investigate if the drop-out rates found in MOOCs could be in part explained by the fact that there are people who register who subsequently decide they are not able to complete for lack of skills.

\subsection{Certification to overcome plagiarism?}

Plagiarism is another issue to be borne in mind.. If certification and accreditation are to become a significant part of the MOOC business models, the credibility of certificates issued by HEIs might be undermined unless breaches of academic integrity, easily achieved via the anonymity of the web, are prevented. Furthermore it is observed that the concept of plagiarism varies across cultures. Wilkinson notes students in certain Asian countries do not see plagiarism as an academic integrity breach, but as a way to show respect to the authority of the content producer [59]. Therefore, universities not only should incorporate plagiarism detection software in their MOOCs, but also emphasize and clarify the principles of academic integrity expected in their programmes.

\section{Conclusions}

This paper examines HEIs' motivations of for making MOOCs and the motivations of learners for registering and completing them. It is clear that these are not simple matters so it is not surprising that there are no simple answers. However there are some useful understandings that we gained from our studies, surveys and interactions with other MOOCers that should be borne in mind when considering motivations.

When it comes to considering institutions' motivations to produce MOOCs, we need to understand that institutions are very much aware of predictions for the way the learning landscape will change with the disruption caused by on-line learning; forward thinking institutions understand that they need to respond to these changes.

Creating MOOCs can be seen as a way of enhancing the institution's reputation, not only in the subject area of the MOOC, but also in the area of quality on-line learning. Furthermore, internally, in the university, the enthusiasm and skills that go into producing MOOCs are the same that are needed to grow internal capacity for engaging with and producing high quality on-line learning courses. In the near future we expect to see universities purposefully using of their MOOC material to add value to their accredited courses. Resulting in much softer dividing lines between accredited courses and MOOCs, on-campus education and off-campus education.

From the point of view of learners there would appear to be two important groups - those that see doing MOOCs as a form of Edutainment; providing intellectual 
stimulation, while another group are those that are seeking educational improvement for the sake of improving their career and life prospects.

MOOCs are much criticised for the high drop-out rates, because small percentages of starters complete their course. But we need to be aware that the motivations of those who register for MOOCS are diverse and may be very different from those who register for university programmes. For a start, many who register have no intention of finishing - they are equivalent to forum 'lurkers', also termed bystanders [60] those who just want to have a look inside the course, and the only way to do this is often to register. Secondly, attitudes to perseverance will vary. Those who find a course less interesting, more time consuming or more challenging than expected may drop-out. Those who signed up at personal cost, believing the study to be critical to their future may persevere.

Finally, we should not assume that all learners intended to complete the whole course. Many learners may only be interested in part of the course, or have time constraints of which they were when they started and thus 'intended' not to complete. Furthermore, MOOCs are free and there is no penalty for failure to complete, many learners are able to drop in (and out) of courses at their own convenience. This should be a cause for educational celebration rather than criticism and represents an opportunity for learner autonomy, choice and independence.

\section{$7 \quad$ Acknowledgments}

The authors would like to acknowledge the work and enthusiasm of Olja Rastic Dulborough and Maraim Masoud two students who worked on internships in the Centre for Innovation in Technologies and Education (CITE) for the summer vacation of 2013, and intern Edmund Baird for subsequent input in 2014. We would also like to acknowledge the respondents who freely gave time to reply to our survey.

\section{$8 \quad$ References}

1. Barber, M., Donnelly, K., Rizvi,S., and Summers.L., An avalanche is coming: Higher education and the revolution ahead. Institute of Public Policy Research (2013)., http://hdl.voced.edu.au/10707/247391

2. Liyanagunawardena, T. R., Adams, A. A., \& Williams, S. A. 2013. MOOCs: A systematic study of the published literature 2008-2012. In The International Review of Research in Open and Distance Learning, 14(3), 202-227.

3. Daniel, J., 2012. Making sense of MOOCs: Musings in a maze of myth, paradox and possibility. In Journal of Interactive Media in Education, 3. http://jime.open.ac.uk/2012/18

4. Herring, S. C. 2004. Content analysis for new media: Rethinking the paradigm. In New research for new media: Innovative research methodologies symposium working papers and readings (pp. 47-66). University of Minnesota School of Journalism and Mass Communication.

5. Krippendorff, K. 1980. Content Analysis: An Introduction to Its Methodology. Newbury Park, CA: Sage 
6. León, M. 2013. Reactions on the Emergence of MOOCs in Higher Education. https://eprints.soton.ac.uk/cgi/users/home?screen=EPrint::View\&eprintid=358803

7. Zimmenan, B. \& Schunk, S. 2001. Self-regulated learning and academic achievements: theoretical perspectives (2nd edition). Routledge.

8. Barnard-Brak, L., Lan, W.,L., \& Osland, V., 2010. Profiles in self-regulated learning in the Online Learning Environments. In International Review of Research in Open and Distance Learning, 11 (1).

9. Marshall, S. J. 2013. Evaluating the Strategic and Leadership Challenges of MOOCs. In MERLOT Journal of Online Learning and Teaching, 9(2), 216-227.

10. Dellarocas, C., \& Van Alstyne, M. 2013. Money models for MOOCs. Communications of the ACM, 56(8), 25-28.

11. MOOCs@Edinburgh Group.2013. MOOCs@Edinburgh 2013: Report \#1 Edinburgh: The University of Edinburgh. http://www.era.lib.ed.ac.uk/handle/1842/6683

12. Yuan, L., Powell, S. 2013. MOOCs and Open Education: Implications for Higher Education. A White Paper. CETIS. Retrieved March, 21, 2013 from www.publications.cetis.ac.uk/2013/667

13. Castells, M. 1996. The rise of the network society: The information age: Economy, society, and culture (Vol. 1). Oxford: Blackwell

14. Williams, R., Karousou, R., \& Mackness, J. 2011. Emergent learning and learning ecologies in Web 2.0. In The International Review of Research in Open and Distance Learning, 12(3), 39-59.

15. De Liddo, A., Shum, S. B., Quinto, I., Bachler, M., \& Cannavacciuolo, L. 2011. Discourse-centric learning analytics. In Proceedings of the 1st International Conference on Learning Analytics and Knowledge (pp. 23-33). ACM.

16. Breslow, L.B., Pritchard, D.E., DeBoer, J., Stump, G.S., Ho, A.D., \& Seaton, D.T. 2013. Studying learning in the worldwide classroom: Research into edX's first MOOC. In Research \& Practice in Assessment, 8, 13-25.

17. Barber, R., \& Sharkey, M.,( 2012). Course correction: using analytics to predict course success. In Proceedings of the 2nd International Conference on Learning Analytics and Knowledge (pp. 259-262). ACM.

18. Marginson, S. 2012. Online open education: Yes, this is the game changer. The Conversation. http://theconversation.com/online-open-education-yes-this-is-the-game-changer-8078

19. Young, J. R. 2012. Inside the Coursera Contract: How an Upstart Company Might Profit from Free Courses, Chronicle of Higher Education. http://www.chronicle.com/article/How-an-Upstart-Company-Might/133065/

20. Economist 2013 .The attack of the MOOCs. The economist Higher Education. http://www.economist.com/news/business/21582001-army-new-online-courses-scaringwits-out-traditional-universities-can-they

21. Weston, C. 2012. MOOCs and other ed-tech bubbles. Ed Tech Now http://edtechnow.net/2012/12/29/moocs-and-other-ed-tech-bubbles/

22. Ptaszynsky, J. G. 2012. MOOCs: The New Internet Bubble in Education? Microsoft Partners in Learning. http://pil-tei.com/blog/moocs-the-new-internet-bubble-in-education/

23. Lawton, R; Katsomitros, L. 2013. MOOCs and disruptive innovation: The challenge to HE business models. The Observatory of Borderless Higher Education. http://www.obhe.ac.uk/documents/view_details?id=929

24. Tauber, T. 2013. The dirty little secret of online learning: Students are bored and dropping out. Quartz http://qz.com/65408/the-dirty-little-secret-of-online-learning-students-arebored-and-dropping-out/ 
25. Kolowich, S. 2013. How edX plans to earn, and share, revenue from its free online courses. The Chronicle of Higher Education, 21. http://chronicle.com/article/How-EdX-Plansto-Earn-and/137433/

26. Kollowitch, S. 2013a. The MOOC 'Revolution' May Not Be as Disruptive as Some Had Imagined. The Chronicle of Higher Education. http://chronicle.com/article/MOOCs-MayNot-Be-So-Disruptive/140965/

27. Catropa, D., 2013. Big (MOOC) Data. Inside Higher Education. http://www.insidehighered.com/blogs/stratedgy/big-mooc-data

28. Parr, C. 2013. MOOC completion rates 'below 7\%. Times Higher Education. http://www.timeshighereducation.co.uk/news/mooc-completion-rates-below7/2003710.article

29. Rheingold, H. (2013) MOOCs, Hype, and the Precarious State of Higher Ed: Futurist Bryan Alexander. DML Central. http://dmlcentral.net/blog/howard-rheingold/moocs-hypeand-precarious-state-higher-ed-futurist-bryan-alexander

30. Davidson, K. 2013. Clearing up some myths about MOOCs. Hastac. http://www.hastac.org/blogs/cathy-davidson/2013/06/11/clearing-some-myths-aboutmoocs

31. Horn, D. (2013) Failing fast, not spectacularly. Clayton Christiensen Institute for Disruptive Innovations. http://www.forbes.com/sites/michaelhorn/2013/08/15/fail-fast-notspectacularly/

32. Lewin, T. 2012. Instruction for masses knocks down campus walls. New York Times. http://www.nytimes.com/2012/03/05/education/moocs-large-courses-open-to-all-topplecampus-walls.html?pagewanted $=$ all \& $\mathrm{r}=0$

33. Drezner, J. 2013. Twilight of the MOOCs? Foreign Policy. http://drezner.foreignpolicy.com/posts/2013/07/22/twilight_of the_moocs

34. Nipper, S. (1989). Third generation distance learning and computer conferencing. In R. Mason \& A. Kaye (Eds.), Mindweave: Communication, Computers and Distance Education. Oxford: Pergamon.

35. Taylor, J. 1995. Distance education technologies: the fourth generation, in Australian Journal of Educational Technology, vol. 11(2).

36. Taylor, J. 2001. Fifth generation distance education, in Higher Education Series, report n.40. Canberra, Australia:Department of Education, Training and Youth Affairs.

37. Fozdar, B.I and Kumar, L.S. 2007. Mobile learning and student retention, in International Review of Research in Open and Distance Learning, 8(2).

38. Caladine, R. 2008. Enhancing e-learning with media.rich content and interactions. Hershey-New York: Information Science Publishing.

39. Siemens, G. 2012a. Massive open online courses as new educative practice. http://es.slideshare.net/gsiemens/open-online-courses-as-new-educative-practice

40. Siemens, G. 2012b. What is the theory that underpins our MOOCs? http://www.elearnspace.org/blog/2012/06/03/what-is-the-theory-that-underpins-ourmoocs/

41. McAuley, A., Stewart, B., Siemens, G. y Cormier, D. 2010. The MOOC model for digital practice. University of Prince Island. http://www.elearnspace.org/Articles/MOOC_Final.pdf

42. O'Toole, R. 2013. Pedagogical strategies and technologies for peer assessment in Massively Open Online Courses (MOOCs). University of Warwick. http://wrap.warwick.ac.uk/54602/7/WRAP_O\%27toole_ROToole

43. Belanger, Y., \& Thornton, J., (2013). Bioelectricity: a quantative approach. Duke Univer$\begin{array}{llll}\text { sity's } & \text { first } & \text { MOOC. }\end{array}$ 
http://dukespace.lib.duke.edu/dspace/bitstream/handle/10161/6216/Duke_Bioelectricity_M OOC_Fall2012.pdf

44. Department for business, Innovation \& Skills 2013. The maturing of the MOOC: literature review of massive open online courses and other forms of online distance learning. UK. https:/www.gov.uk/government/uploads/system/uploads/attachment_data/file/240193/131173-maturing-of-the-mooc.pdf

45. Bates, A.W., 1995. Technology, e-learning and distance education. Routledge: Oxon

46. Clow, D. (2013, April). MOOCs and the funnel of participation. In Proceedings of the Third International Conference on Learning Analytics and Knowledge (pp. 185-189). ACM.

47. Inside Higher-ED. 2013. Udacity Project on "pause". http://www.insidehighered.com/news/2013/07/18/citing-disappointing-student-outcomessan-jose-state-pauses-work-udacity

48. Strither, J.B. 2002. An assessment of the effectiveness of e-learning in corporate training programs, in The international review of Research in Open and Distance Learning, vol.3, n.1. http://www.irrodl.org/index.php/irrodl/article/viewArticle/83/160

49. Driscoll, M. 2001. Building better e-assessment, in Learning circuits, ASTD. http://www.astd.org/LC/2001/0601_driscoll.htm

50. Radenkovic, S., Krzavac, N. \& Devedzic, V. 2010. An assessment system on the Semantic Web, in Devedzic, V. \& Gasevic, D. (ed.), Web 2.0 and Semantic Web, annals of information systems. USA: Springer.

51. Luján, S. 2012. Preguntas y respuestas: ¿Qué son los MOOCS? http://desarrolloweb.dlsi.ua.es/cursos/2012/que-son-los-moocs/preguntas-respuestas

52. Cookson, P 2013 Are MOOCs the Answer? Preserving Value of Higher Education. The Quick and the Ed. Posted on 23 August 2013. http://www.quickanded.com/2013/08/aremoocs-the-answer-preserving-the-value-of-higher-education.html

53. Blumenstyk, G., \& Carlson, S. (2012). For whom is college being reinvented? The Chronicle of Higher Education, 17.

54. Engler, C. 2013 MOOCs and Megatrends: A Prediction Comes True. Evolllution. http://www.evolllution.com/distance_online_learning/moocs-megatrends-prediction-true/

55. Leckart 2012. The Stanford Education Experiment Could Change Higher Learning Forever. www.wired.com/wiredscience/2012/03/ff_aiclass/

56. Sloep, P. 2013. MOOCs, what about them? Some moral considerations. In Stories to TEL. http://pbsloep.blogspot.nl/2013/01/moocs-what-about-them-continued.html

57. Osvaldo, C. 2012. MOOCs and the AI Stanford like Courses: Two successful and distinct course formats for massive Open Online Courses. In European Journal of Open, Distance and E-Learning. http://www.eurodl.org/?article $=516$

58. Brown, S. 2013. MOOCs, OOCs, flips and hybrids: the new world of higher education. In ICICTE 2013. Proceedings (pp. 237-247). http://apps.webofknowledge.com/full_record.do?product=UA\&search_mode=GeneralSear ch\&qid=1\&SID=W1xAnAorTZUmTypaXSZ\&page $=2 \&$ doc $=14 \&$ cacheurlFromRightClic $\mathrm{k}=\mathrm{no}$

59. Wilkinson, L. R. 2008. ESL academic writing and plagiarism. In The Internet TESL Journal, 14(7).

60. A. Anderson, D. Huttenlocher, J. Kleinberg, and J. Leskovec, "Engaging with massive online courses," Proc. 23rd Int. Conf. World wide web (WWW'14), pp. 687-698. 